\title{
Prison, Architecture and Social Growth: Prison as an Active Component of the Contemporary City
}

TYPOLOGY

\section{Luigi Vessella}

\begin{abstract}
How do we treat those who make mistakes? And what does this have to do with architecture? The paper will investigate the role of architecture in the design of prisons in order to understand how we could develop a project for a jail that is a place for both punishment and rehabilitation. The effectiveness of a prison is not given only by the efficiency of the justice system in force, but also by the articulation of spaces and by the quality of the architecture. The contradiction of the prison is revealed by its need to respond to two opposing demands: punishment and reintegration. This paper investigates the possible design approaches aimed at designing a new jail typology, through an attempt to "break" the macro-themes that characterize the building of the prison and within these dichotomies work on the "boundary-line" between opposing realities: freedom-constriction; openness-closure; etc. If prison architecture were brought back into the debate regarding contemporary design culture, it could have a significant impact for society especially in terms of opportunities and cultural growth.
\end{abstract}

Keywords: penitentiary architecture, responsibility regime, prison typology, open prison architecture, behavioral rehabilitation

Most societies that today have adopted Criminal Law as an instrument for regulating the penal system in an egalitarian manner, despite the fact that they have adopted and consolidated the principles of re-education and social re-insertion of the detainees ${ }^{1}$ after serving their sentence, find 
themselves searching for alternative answers to an unsolved issue which weighs heavily on all communities, both from the economic and social points of view.

When analysing the current situation of penitentiary systems in Western countries (Italy, Spain, the United States, etc.), the difficulties and incoherencies that continue to exist to this day regarding the role of prison in contemporary society, as well as the objectives it should pursue and the concrete results it should obtain, result quite evident.

Considering that the essence of the punishment as envisaged by the constitutions of democratic states (the limitation of the freedom of movement within a specific enclosed space) is not to be put into question here, it is however necessary to present a series of hypothesis for re-thinking the nature and features of the material and spatial structure in which the punishment is carried out. One example is the establishment of new conceptual principles of a typological nature and a new vision of the prison understood as an active component of civil society capable of interacting with the surrounding context and of generating relations and interchange with the outside world. This can help envisage an institution which, however anchored on some basic principles, can express the new vision and the new interpretation of the punishment. Although it is undeniable that there is a correlation between a certain philosophy of punishment and its materialisation in penitentiary institutions, it is also true that this materialisation is not necessarily aimed at transmitting, both from the inside and from the outside, the image of a closed, unsettling and isolated reality, lacking in any opportunities for renewal. ${ }^{2}$ In fact, it is precisely beginning from the appearance of the penitentiary building, that is of its architecture, that in synergy with other fields of study it is possible to attempt a general re-thinking of contemporary penitentiary structures, trying, however, to limit the recourse to detention in prison. For some time now prison has been defined as "an expensive way of making bad people worse," ${ }^{3}$ and for this reason, without wanting to debate on the functions and on the deep reasons for the existence of the prison as a correctional instrument in our society, it is worthwhile to imagine alternatives to the traditional way of conceiving it and to the role it plays in contemporary cities. Prison as we know it today ${ }^{4}$ originated in the eighteenth century, when revolutionary movements and the ideas of the Enlightenment brought about a radical transformation of society, from the political as well as the social and economic points of view, drastically modifying the existing worldview, the economic organisation and the respect for human rights.

The origins of prison as a physical place for holding prisoners in fact predate the Enlightenment and have roots in the historical moment when reclusion starts to be considered as an essential tool for the correction of the offender. He is no longer considered as a social reject to be discarded (as it had been until then) but rather as the subject of a process intended to a transformation of social behaviour. The transformation of ideas 
regarding punishment began to develop around the fifteenth century. Religious institutions were the first to conceive it as a possibility for rehabilitation rather than merely for affliction, through the establishment of Correctional Homes (which became widespread in Europe around the end of the sixteenth century). Before this time there was no clear division between the "trial" and the "punishment," and consequently no specialised architectural structures exclusive for the reclusion of the condemned. The Catholic Church was the first to build a It is attributed to the Catholic Church the first modern-type penitentiary structure, the prison of San Michele in Rome, designed by architect Carlo Fontana in 1704. This is the first example of a building which combined considerations regarding architectural form and treatment regime. The cultural process which led to the development of a modern idea of the prison is very complex and articulated, and was based on the fundamental contribution of some illustrious personalities who determined the evolution of the idea of the punishment and generated a new perspective regarding condemned criminals. In particular John Howard ${ }^{5}$ who, through his work, helped reform the British penitentiary system and influenced the transformation of many other European penitentiary systems, and Cesare Beccaria who, with the publication of the treaty On Crimes and Punishments (Dei delitti e delle pene), ${ }^{6}$ defined criminality in secular terms ${ }^{7}$ and opposed torture and the death penalty as instruments of the state.

There is no space in this text to adequately describe the long process that led to the formation of the idea of the punishment in contemporary society, but it is worth recalling Michel Foucault's groundbreaking essay Survellier et punir: Naissance de la prison (1975) which describes both the origins of the prison and its role in contemporary society.

The in-depth reflection expressed in the essay regards the concept of the punishment and the role that is attributed to it in modern society in relation to the state, as well as the complex succession of cultural changes that have turned the prison into the main form of punishment in Western societies. In the essay, prison is analysed within a wider ideological context that includes other total institutions such as schools, army barracks and factories, and the mechanisms which regulate the existence of the said institutions in contemporary society. Foucault's thought has influenced many fields of study, which have further modified the concept of punishment and have contributed to modify and define contemporary thought regarding the function and execution of punishment in society today.

Before carrying out an in-depth analysis of the subject in question, it is necessary to define the limits of the field of study and to clarify the interpretation of some concepts. When looking at the various penal systems currently in force in Western countries (Europe and the United States specifically), it is evident that the general situation of penitentiary structures is critical and that the current punitive methods are often inefficient and produce meagre results in terms of social reinsertion. In 
Europe, the penitentiary systems of many countries (among which Italy, Spain and England) present situations of overcrowding and degradation, as well as a chronic lack of economic and human resources; this renders the penitentiary treatment of detainees inefficient and costly. Analysing the detainee population in Europe, it can be seen how the majority of people who are in prison have been detained due to the commission of misdemeanours, generally of a non-violent nature (theft, bankruptcy fraud, use of illegal drugs, illegal immigration, etc.); despite this, the said detainees are subject to the same penitentiary regime as the prisoners who are in jail for the commission of more serious crimes. ${ }^{8}$ Analysing in depth the composition and current conditions of penitentiary structures in the main Western countries, it can be seen how, with a few exceptions, they are not adequately organised and differentiated into progressive levels of security, and are therefore not properly adjusted to the features and needs of the various segments of detainee population housed in them.

Considering the current composition of the detainee population it would be preferable for penitentiaries to be organised and differentiated according to the typologies of prisoners. In fact we believe that housing within the same structure detainees who belong to different typologies and with different needs in terms of security, control and rehabilitation treatments can present problems in terms of efficiency and the results of the envisaged penitentiary treatment. Instead, we propose the conception of penitentiary structures specifically designed for clearly defined profiles of detainees, rather than structures that are "good for all cases," which indistinctly house people who need different types of attention and treatment. It is obviously not a question of penalising misdemeanours or eliminating prison sentences as punishment for non-violent crimes, but rather organising penitentiary structures into security circuits that are differentiated in accordance to the type of detainee and the level of security required. In this way the re-education treatment can be better focused and regulated to the specific needs of the detainees in each of the penitentiary circuits that the state considers as necessary in relation to the social conditions of each country. This could help avoid the homogenisation and standardisation of penitentiary treatment, which makes it inefficient, costly and untenable, as the data from the Committee for the Prevention of Torture and Inhuman or Degrading Treatment or Punishment (CPT) demonstrate.

Additionally, when analysing the main penitentiary structures existing today, it is evident how the current conception of the prison and the interpretation of the sense of security has broken the link that prisons historically maintained with the city to which they belonged. We can trace this from the first examples of Correctional Houses in Northern Europe to nineteenth century penitentiaries, enclosed in themselves but firmly inserted in their urban context (for example, San Vittore in Milan and Pentonville in London). The most important penitentiaries today are located far away from urban centres, in isolated communities, or in the suburbs of large cities, thus at the margins (both physically and figuratively) of 
society. In view of this, it is important that penitentiary structures should be differentiated not only in terms of treatment and prison regime, but also in terms of architectural features and appropriate location criteria, in relation to the various typologies of detainees and their specific reclusion, security and rehabilitation requirements.

It is also believed that, as affirmed by the General Assembly on Criminal Enforcement (Stati Generali sull'Esecuzione Penale), places of detention should once again involve the work of project architects, and no longer be an exclusive prerogative of institutional technical agencies. In this regard, focusing our attention on Europe, we can look at some interesting examples in which the architecture and the interior spatial organisation were capable of ascribing to the prison building an active role within the city and at the same time of offering a positive contribution to life in detention through a different typological model for the space used for everyday activities. The case studies presented below show, on the one hand, the awareness of the responsibilities of the architect, or project team, in the design of such an important building for both city and society, and on the other, a sensibility towards not only the more general aspects of prison design, but also to the details and ordinary elements which in the context of the prison assume a fundamental role, both for detainees and operators.

\section{THE FUNDAMENTAL PRINCIPLES OF THE NEW PENITENTIRAY ARCHITECTURE}

Although prisons are very complex structures in which many factors take part in terms of performance and efficiency, and therefore the issues related to them need to be tackled through a multi-disciplinary approach, in this brief essay the attention will focus mostly on aspects that are inherent to the architecture of the prison, both at the urban scale and that of the building itself, with references as well to some issues which include management, organisational and social aspects within the penitentiary structure. Some penitentiary activities, in order to be carried out in accordance with the law or international regulations, ${ }^{9}$ need a specific spatial structure, which satisfies certain requirements and specific standards, especially in terms of size. All of this can be respected only if the prison is envisaged, both at the institutional and cultural levels, as a tool for rehabilitation and for providing opportunities, rather than only as a place of segregation and social exclusion. ${ }^{10}$ Translating these concepts into architectural terms, it could be said that if the prison continues to be envisaged only in terms of security and control, it will remain the institution that we know. On the contrary, if architects are given the opportunity to provide for aspects regarding the interior quality and comfort for the users of the structure, it will be possible - as the examples show - to ascribe an active role to the penitentiary, including a healthy relationship with society outside the prison, which can thus become an asset for society at large. 
The hypothesis that is presented here derives from the assumption that the various types of detainees should be differentiated into structures that are designed based upon the different needs of the various segments of the prisoner population. This view is based upon the premise that architecture can, and must, contribute through appropriate projects to these varying types of custody requirements into which the penitentiary system can be subdivided. Although it would be preferable to rethink typological schemes and spatial organisation at all levels of security (from minimum to maximum), it is easier to begin by providing detailed indications regarding prisons belonging to the minimum-security circuit. Due to their lower levels of control, minimum-security institutions can more easily accept and adapt to new typological experimentation and to design solutions that are not as bound to the traditional rigid prison models which have been unimaginatively replicated throughout the territory.

As mentioned before, the themes included in the definition of a new architectural conception of the prison take into consideration aspects at the urban scale even before defining with precision the typological features of the building. Every State certainly has its own particularities and features, its traditions and customs, but if we pay attention exclusively to European nations, we can overlook the differences that characterise every social system and penitentiary model, and consider only those aspects that are essential and fundamental in all systems. This process of simplification is partly justified by the fact that the tradition on which the main penitentiary systems is based has a common origin, which has now been shared for decades through the adoption of international agreements and regulations, as well as by the fact that, at a general level, the respect for human rights and for the dignity of individuals is founded on universal tenets that are now shared worldwide.

In view of this, it is appropriate to make a clarification regarding the penitentiary system in the United States, which presents features that are very different from those adopted by the countries belonging to the European Union. This makes it difficult to carry out comparisons or to import or export solutions between the two contexts. In the United States the situation of prisons is generally tragic, as it can be seen in the last report published by the International Centre for Prison Studies at King's College in London, ${ }^{11}$ which shows how detainee population has reached numbers of up to 2,200,000 people, with the second highest rate of detention in the world, 698. ${ }^{12}$ The specific mechanisms through which penitentiary services are subcontracted to private entities, prefigures a situation that is very different from that of Europe, from the cultural, social and economic points of view. To this, it is added the fact that the death penalty is still practiced in some states of the American Union. These factors result in a fundamental ideological difference between Europe and the United States which, from its fundamental principles, has implications throughout all levels of the organisation and management of the penitentiary system. Thus, in order to seek new hypotheses for 
the development and enhancement of the penitentiary system, it is more convenient to focus on the European context. In this way certain positive tendencies may be highlighted. These are often still in an experimental phase, yet begin to show their first positive results.

The countries which present more innovations regarding the adopted penitentiary model are Norway, Denmark, Spain and Austria. Each country expresses these innovations in different ways. Some, like Norway and Denmark, have designed very modern and expensive structures, innovative in terms both of the spaces - interior furnishing and decoration - and of the security and technological systems adopted, which collaborate with the proper carrying out of advanced penitentiary treatment methods. Other countries, such as Italy and Spain, have mostly aimed at the transformation of penitentiary models, only partially modifying the existing penitentiary structures. It is necessary, however, to bear in mind that Italy and Spain show a continuous presence of critical, and sometimes even emergency situations, whereas other countries, such as Norway, Austria and Denmark have consolidated good practices which have transformed them into ordinary practices for the design, management and organisation of penitentiary structures. The benefits of this approach are evident as it can be seen by comparing the data regarding the detention rate and the percentage of recidivism. In Italy the detention rate is close to 103, in Europe it is 128 and in the world $144,{ }^{13}$ but there are remarkable exceptions, such as Norway, with a detention rate of 71 , and Denmark with 61 . The same disparity exists in the rate of recidivism: ${ }^{14}$ in Italy recidivism is higher than $67 \%$, whereas in Norway the percentage of recidivism is between 16 and $20 \%$. This same rate in the United States reaches a staggering $76.6 \%$. ${ }^{15}$

These numbers cannot be ascribed only to the bettering of the spaces and of the quality of services within the prison, but research carried out on the Norwegian penitentiary system show that the architecture and quality of the spaces does play a fundamental role in addressing the challenge of creating a penitentiary system that is both efficient and useful to society. The words of the Director of Bastøy prison are in this sense exemplary: "In the law, being sent to prison has nothing to do with putting you in a terrible prison to make you suffer. The punishment is that you lose your freedom. If we treat people like animals when they are in prison they are likely to behave like animals." 16

These figures show how a new organisation of the penitentiary system is needed, beginning from its material structure. The question, however, must be addressed at the cultural level. The transformation of the cultural stance is necessary in order to bring about an interpretation of the prison sentence as an opportunity for the renewal and rehabilitation of the detainees, which then becomes expressed by the resulting penitentiary models through concrete elements such as work, education, interchange with the outside world, and the organisation of individual and collective spaces. 
The arguments regarding the new idea of the prison refer to models for minimum and medium security penitentiaries, but nothing excludes the possibility of extending the elements in question to all types of prisons, while limiting as much as possible the construction of maximum security institutions. The aspects that characterise the new way to conceive the prison regard:

a) The location of penitentiary buildings in relation to the urban context and to the structures that intervene in the penitentiary system. The penitentiary building must be capable of establishing a relationship with its surrounding context and of generating interchange with the outside world so as not to become an impenetrable element, unresponsive to the stimuli coming from the city. The prison must no longer be conceived as a city within the city, as in the past, but rather assume the functions of an urban neighbourhood, and be placed in continuity with the surrounding urban fabric. This permits the creation, in precise and well-chosen points, of "moments of osmosis" between the inside and the outside, in a dialectical relationship with the active components of the surrounding social context.

b) The penitentiary structure, even when articulated into several buildings, must however be based on a compact typology so it can be inserted without discontinuity into the urban fabric. It must be conceived as a complex structure with entrance and exit flows, and must offer its non-residential spaces, especially next to the entrance, to the outside community, so as to allow the prison to become a place for supporting urban collective culture, ascribing to it a role as linkage between the inside and outside worlds.

c) The elimination of the impenetrable wall as a necessary condition for overcoming the "fortress" effect. The re-thinking of the external wall, the boundary, as we are used to imagine it today, must be abandoned in favour of a more permeable solution, both from the visual and the material point of view. The substitution of the wall with a porous, inhabited perimeter, could confer to the boundary a greater "thickness" that allows organising within it spaces for penitentiary functions that are not strictly related to detention, capable of hosting the external community and make it come into contact with the "enclosed" community living in the prison.

d) The prison building must adopt spatial solutions which follow more open custody models in which the cell is no longer the central element of prison life. The prison must no longer be a nondescript container of cells and must become a well-articulated structure capable of satisfying the requirements of collective as well as of individual life. There must be alternation and variation between spaces. The dimensions and measurements of the environments must be proportionate to the periods of time the 
spaces are occupied and to the number of users admitted to them simultaneously, as well as adequate for the specific functions to be carried out within them. The various sections of the structure must not be mono-functional, but rather tend to a multi-functionality, so as to alternate open spaces for social activities and closed spaces for the various activities envisaged by the rehabilitation treatment programmes. The dynamic succession of dense and rarefied spaces must be as close as possible to that of everyday urban normality.

e) The cell must lose its role of central place in prison life, giving way to a model of the prison organised on the model of self-sufficient residential units (residential nuclei). Within each residential unit the detainees can self-manage their time and organise the distribution of the responsibilities regarding their common areas, abandoning the model of undifferentiated distribution of cells. Residential units must present an alternation between individual spaces, for the moments of privacy, and collective spaces for moments of social interaction. The atmosphere within the interior space must reproduce, at least partially, the familiar effect of collective structures, ${ }^{17}$ so that the organisation of space may play a role in the process of rehabilitation and help in fostering an attitude of social cooperation.

f) The size of the spaces, beginning with the bedrooms, both in residential units and in other types of functional organisation, must respect the minimum dimensions established by national and international regulations of the C.P.T. and the European Court of Human Rights. The dimensional standards, as only regulatory tool, have been much criticised and doubt has been cast as to whether they provide an effective benefit to collective structures, either of a social or popular nature. Adopted in a deterministic manner, without additional criteria for choosing the minimum dimensions, they seem sterile and incapable of ensuring the levels of quality required by complex structures such as a prison. If the dimensional parameters are not determined in relation to the ways in which the spaces are used, and the duration of the usage, the resulting spaces will be inadequate for satisfying their purposes, to the point of becoming generators of anguish and depression. These parameters, however, can be kept as reference for penitentiary institutions, if they are then appropriately related to the ways in which the spaces are used.

g) The new penitentiary structure must overcome the model of confinement of detainees within the detention section even if it belongs to the open cell typology, and envisage differentiated levels of autonomy of movement for every detainee. Some institutions already use technological systems that envisage the use by the detainees of magnetic cards which give them access to certain functional areas of the prison, based upon their duties and 
treatment activities. This method of management of the internal flow, on the one hand can make the participation of detainees in therapeutic activities easier, thus helping them to fully express their personality, and on the other allow prison operators to better get to know the detainees inside the areas where they spend most of their time.

h) In order for work and education to have an active role in the process of re-education, it is necessary to provide adequate spaces which can take on the symbolic value of spaces for cultural and social emancipation, fundamental elements for a positive reinsertion into society. The educational and work programmes have proven to be essential for the reinsertion of the detainees and have a direct effect on lowering the rate of recidivism (Jovanic, 2011). Some studies have proven that education, work and detention are closely related and that offering the detainees the opportunity to better their work capacity and cultural quality means offering them an enhanced possibility to reconstruct their life after prison. ${ }^{18}$ The classroom, as well as the workshop, must be conceived so as to favour learning and incentivize interaction and cooperation between detainees and operators, marking a distance - as much as possible - with the features of closure which characterise spaces of reclusion.

i) Meals, such as lunch and dinner, must be held in common so that this activity assumes once again its usual and normal value as a moment of social interaction. For this reason, the appropriate spaces that respect regulations in terms both of hygiene and security must be made available. As we can read in the Final Document of the General Assembly on Criminal Enforcement, ${ }^{19}$ the preparation and consumption of meals is of the utmost importance since it represents "one of the few elements that recall the everyday life outside the walls, in addition to being one of the few activities that the detainees can carry out autonomously: it is a way for reaffirming individual identity and for maintaining links to one's own family, as well as for interacting socially with fellow inmates." Instead of providing common dining-halls where the entire detainee population eats at the same time, smaller areas can be devised where small groups of detainees can autonomously administer, prepare and eat their meals.

j) The interior furnishing and decoration and the treatment of surfaces, both horizontal and vertical, as well as various security systems in use today must be rethought in function of a lesser visual and material impact. The materials and the colours used must contribute to the creation of a welcoming and comfortable environment, with a good degree of way finding and with a lighting that is adequately related to the specific activities undertaken in each space. 
The above described 10 elements have been deduced observing examples carried out in Europe and North America. They seem to represent the main elements on which to base the design of a new typology of penitentiary institution. A penitentiary model that is different from the preceding models not only in name, but rather a structure which is truly new in its very essence, and which expresses through its architectural configuration the aims of rehabilitation and social reinsertion. The described elements express the idea of a prison centred on the opportunities for rehabilitation of the individual, and no longer only on segregation and exclusion. The limitation of freedom becomes the only element of punishment that the Rule of Law inflicts on those who transgress certain rules, and this new penitentiary model clearly represents this stance. At the centre of the new detention model is the detainee himself, who is considered as an active participant in the process of re-education. This cultural threshold permits a society to express a detention model centred on individual responsibility and on the possibility of self-management of part of their everyday life by the detainees. This represents the "jump" which allows a society to establish a properly functional penitentiary apparatus. A penitentiary system which is capable of rehabilitation rather than correcting, of including rather than isolating, and of creating a community which, however enclosed as a result of having committed a mistake, is part of the social structure, and as such exists permanently, notwithstanding the social re-insertion of the individuals who belong to it.

\section{CASE STUDIES}

With the purpose of integrating and verifying the information obtained from the scientific literature and from official documents and reports (European Union, UN, C.P.T. ${ }^{20}$ ) the detailed examination of a series of case studies was undertaken. The chosen examples are significant regarding the topic at hand because they offer interesting starting points for further reflection and in-depth analysis on the subject of the design of minimum-security penitentiary institutions. The case studies were selected on the basis of certain specific parameters listed below, that were considered essential for evaluating the features and implemented design solutions. The buildings in question represent the expression of interesting and original spatial and architectural features, which make them stand out among the common current production of this typology of structures. These features concern mostly the morphology, functionality and organisation of interior and exterior spaces. The identified features are those that were deemed more significant for the definition of general design criteria.

The analysis of the case studies was carried out with the purpose of gathering - through the examination of plans and drawings - documents, information of a general nature (type of institution, dimension, location, etc.) and a series of empirical principles not yet codified by the scientific literature, but already widespread within the culture of the project. 
The idea behind the analysis of the case studies is that of tracing an architectural typology and a reference model for the planning and design of future penitentiary structures. This is carried out by identifying, through the examination of the built examples, the characteristics of the configuration and organisation of spaces, as well as the variables and constants in the design of minimum-security prisons. The wish to trace the architectural typology does not stem from a desire to identify a "structural model" to replicate in future projects. Rather, it comes from a desire of setting down a series of principles, ideological motives, functional constants and types of spatial organisation that may constitute guidelines, on both cultural and symbolic level, for the design of minimum-security penitentiary structures. In order to ascribe theoretical value to this premise, it is perhaps useful to recall Quatremère de Quincy's definition of type:

"The word 'type' presents less the image of a thing to copy or imitate completely than the idea of an element which ought itself to serve as a rule for the model. [...]. The model, intended as the practical execution of art, is an object that must be repeated exactly as it is; the type, on the contrary, is an object upon which anyone can conceive works that have no resemblance to each other. Everything is precise and given in the model; everything is more or less vague in the type." 21

Since the type is a concept that is construed a posteriori, that is after the observation of a series of concrete examples, one may attempt to identify among completed projects those typological constants which have reached an adequate level of stability over time, and may thus be considered as valid, precisely because they have been verified by historical experience. Through the experience of type one may "take advantage of the experience accumulated over time, especially considering the validity that those forms will continue to have in the future." ${ }^{22}$ The type is thus not a precise form, but rather a general framework or a 'project of form' that prefigures possibilities and alternatives.

The parameters for deciding which case studies to choose were the following:

- morphology

- distributive features

- functional and spatial organisation

- management systems

- levels of security and control

From the preliminary considerations, the listed features seem to be those that contribute most to the definition of new typologies of penitentiary institutions and that are capable of characterising a penitentiary structure not only on the basis of its custody and isolation functions, but also upon functions related to housing and rehabilitation. 


\section{Halden Prison, Halden (Norway)}

The Halden penitentiary complex, situated approximately $100 \mathrm{kms}$ to the south-east of Oslo, was inaugurated in April, 2010, and is the feather in the cap of the Norwegian penitentiary system (Fig. 1). The project constitutes the most innovative example in the field of penitentiary architecture for the application of the responsibility regime, and the prison is configured as a detention facility for both the rehabilitation of inmates and behavioural research. Designed by the HLM arkitektur studio in collaboration with the Erik Møller arkitekter studio, Halden prison was built over a period of ten years and at a cost of approximately 200 million euro. The main objective for both the entity who commissioned the prison and for the architects who designed it was that of making the penitentiary institution resemble as much as possible the outside world, so as to establish a way of life based upon responsibility and self-determination. The 252 inmates are busy in work or study activities during the day and spend most of the time outside their detention rooms. The prison is organised into several separate pavilions immersed in the green of the garden, and within the pavilions the inmates are free to move and to organise their leisure activities together. The detention sections house 10 inmates each and include, in addition to the rooms for

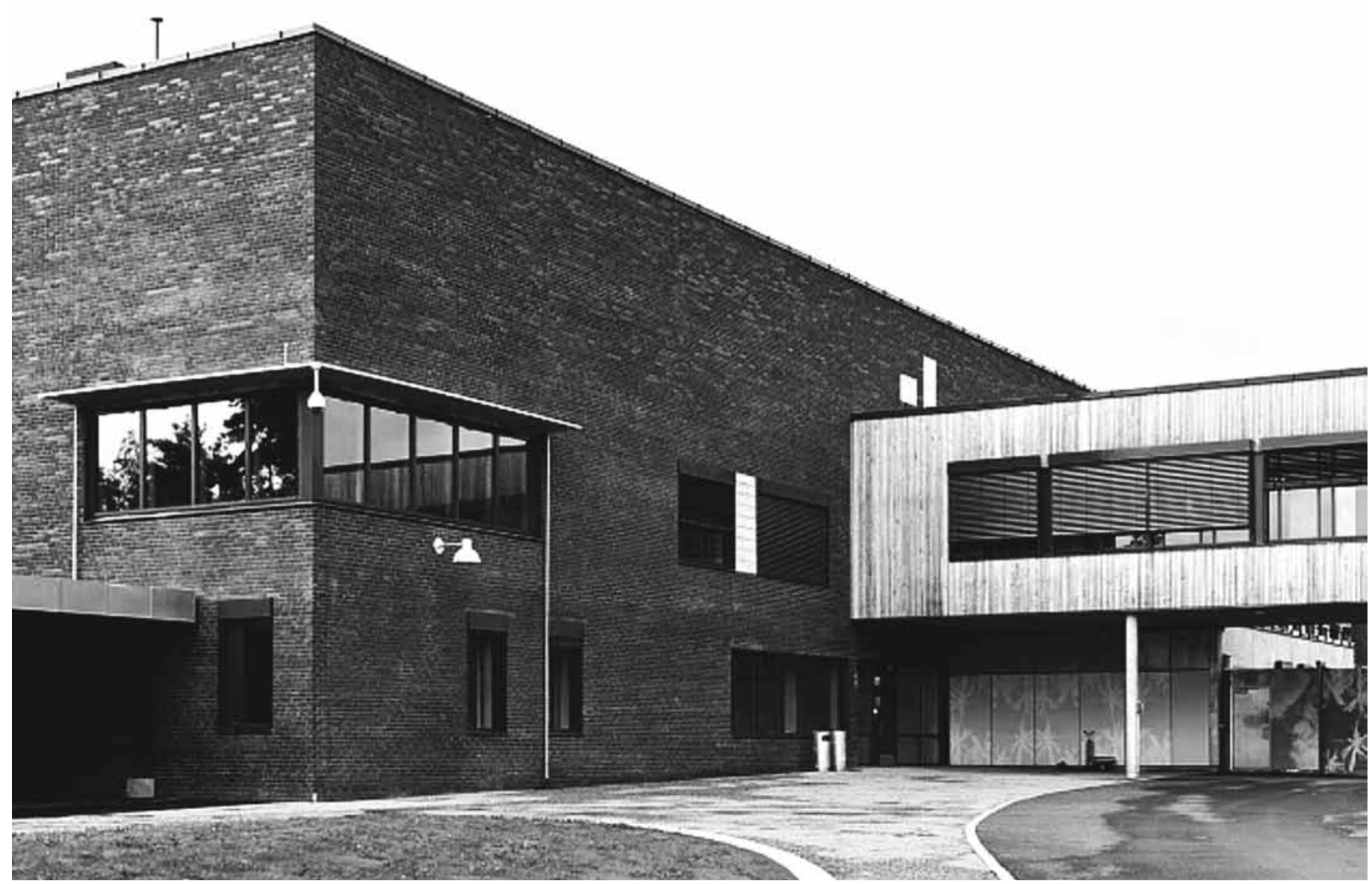

Figure 1. Halden Prison, Halden (Norway). The entrance building. 
sleeping (Fig. 2), a living-room (Fig. 3), a dining-room, a fully equipped kitchen and a multi-purpose room. The inmates can prepare and eat their meals together, as well as do their cleaning and manage their expenses in common. The entire area within the walls is laid out as a garden, with trees, benches and jogging lanes, and is visited on a daily basis by the inmates whenever they have any free time. In addition to the detention sections, the workshops and the school, the prison includes a recording studio, a common kitchen and guest quarters for relatives who come to visit the inmates. In addition to the responsibility regime, Halden prison is characterised by the architectural solutions used; the architects in fact strived - both regarding forms and the choice of materials - to limit the alienating effects caused by detention, and to imagine a structure that would recall the least possible a detention centre. The prison wall was also the object of intense research, and was partially camouflaged with the use on the one hand, of a curved layout and tall trees and, on the other, through a series of murals and graffiti of high aesthetic quality painted by contemporary artists. Another element in the Halden prison that attenuates the sense of constriction and alienation is the abolition of all the traditional internal security devices (bars on windows, fences, armoured doors, etc.), which are replaced by technologically advanced systems. All the elements above described contribute to the establishment of a penitentiary institution that is respectful of both human rights and the individual personalities of the inmates. Halden Prison is a highly innovative institution for the qualified treatment and behavioural rehabilitation of the detainees and it looks ahead to the future and attempts to overturn the old principles and belief in segregation and suffering as part of the penalty.

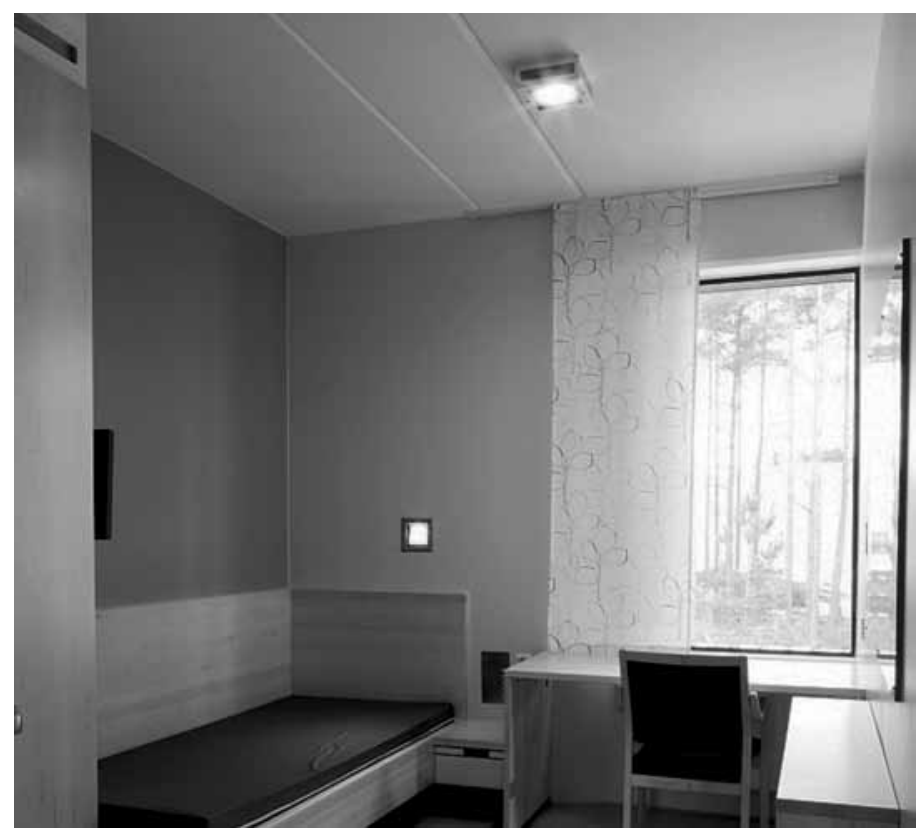

Figure 2. Halden Prison, View of a bedroom.

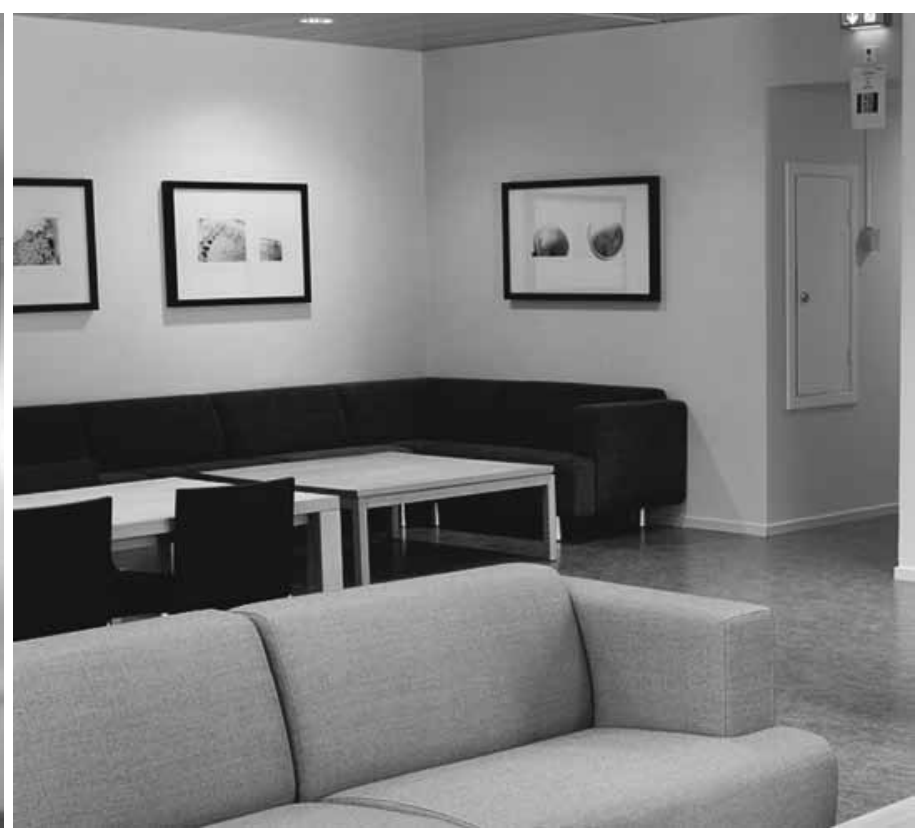

Figure 3. View of the living-room of the detention section. 
New Justizzentrum, Leoben (Austria)

The building designed by the group of Austrian architects Hohensinn Architektur, inaugurated in 2004 , is not only a minimum-security prison, but also a proper public structure at the service of the city. In the description of the project, the architects say that the objective was not to design a new courthouse for the small city of Leoben, but rather to build an open structure at the service of the population of the city.

The justice centre comprises two main sections: the first, with a glass facade looking towards the city (Fig. 4), is the courthouse itself, which includes all the offices of the courthouse and of the public prosecutor; the second, placed on the back of the building, houses the minimum security prison (Fig. 5). The prison can house 125 detainees subdivided into four separate sections. Each detainee has a single bedroom (Fig. 6), normally furnished, and has access to the common spaces present in the section in question: dining-room, kitchen (Fig. 7), living-room, garden and loggia. The prison also has a gym, a sports centre, covered gardens and terraces, in addition to the services and spaces for both recreational and rehabilitation activities. The inmates are free to move within their sections without the need of security agents, and can reach the areas for work and educational activities independently. The detention sections are designed as though they were shared apartments, with all the comforts found in a normal civilian residence. They are furnished with sofas, armchairs, tables, and flat-screen televisions. Through the quality of spaces, materials and

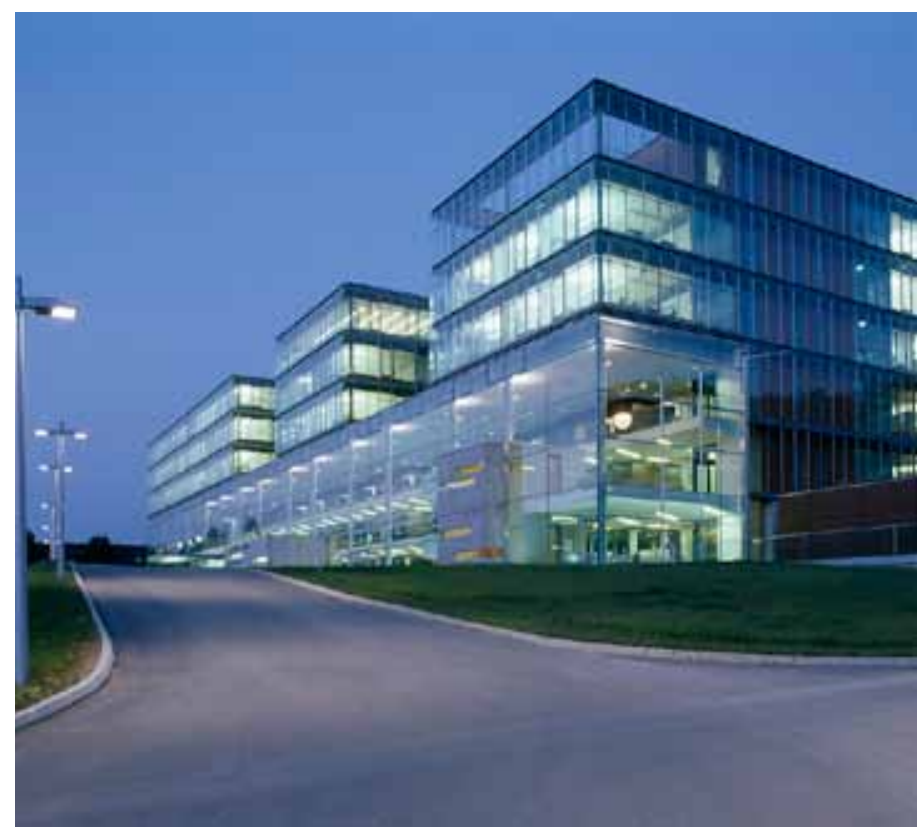

Figure 4. New Justizzentrum, Leoben (Austria). View of the facade as seen from the city of Leoben.

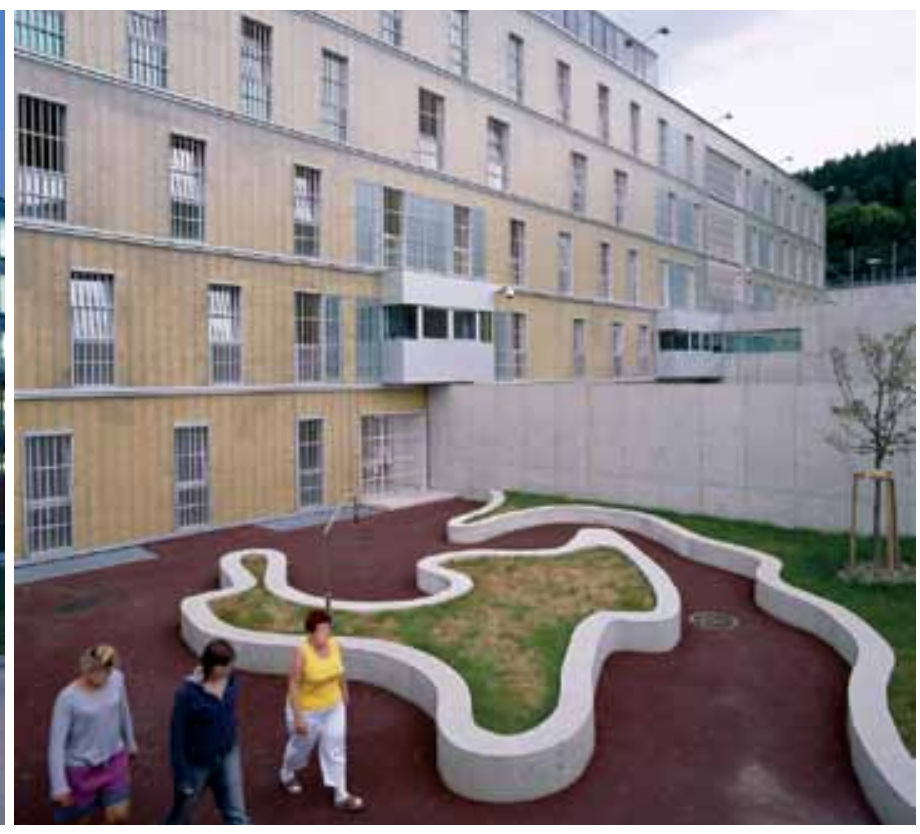

Figure 5. View of the garden and part of the facade of the detention building. 


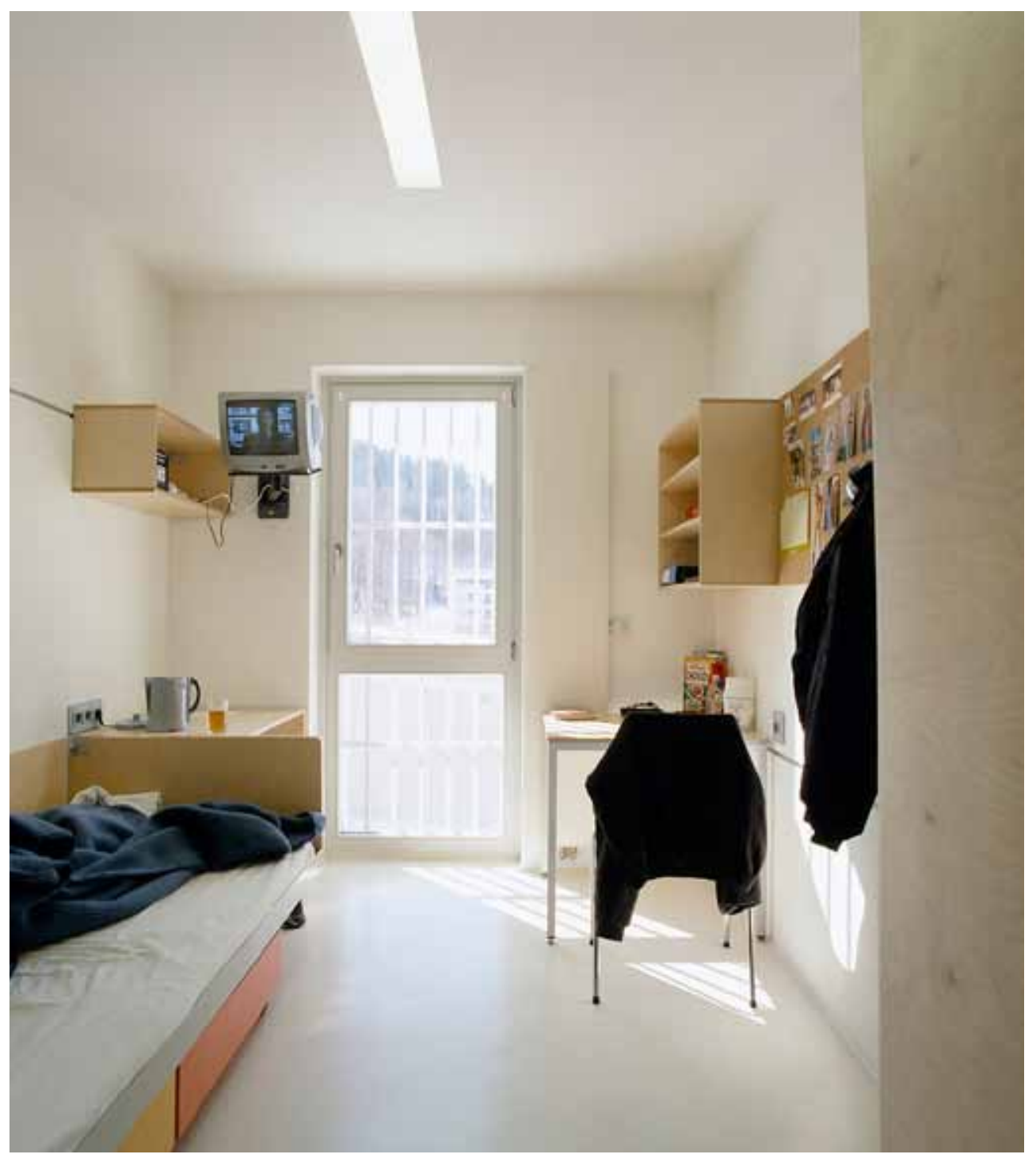

Figure 6. New Justizzentrum, Leoben. View of the inside of a bedroom.

furnishings, the living environment aims to generate positive sensations and stimulate social interaction among the detainees so as to render the detention period less traumatic and to produce a true transformation in the behaviour of the inmates. Special attention was placed on the design of the gardens and courtyards where the inmates spend their leisure time participating in sports and recreational activities.

The architects attempted to reduce to the minimum traditional security devices such as bars on windows and interior gates and fences in order to guarantee the ease of movement and reduce the sense of constriction. A location was chosen for the new jail in the proximity of the urban centre of the small city of Leoben, so as to permit the new building to establish an interaction with the surrounding urban context. 


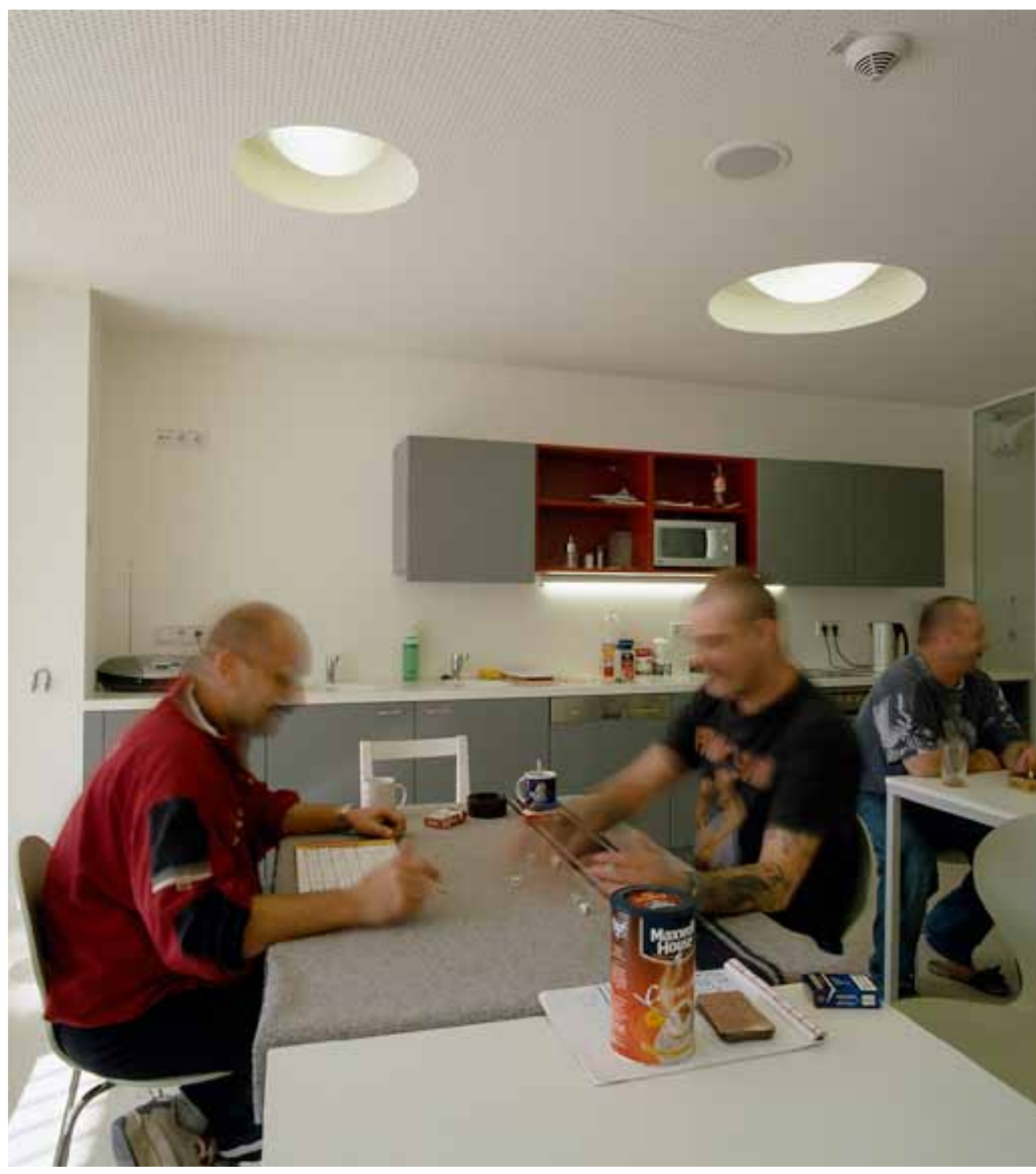

Figure 7. Justizzentrum, Leoben. View of the dining-room and of the kitchen of the detention section.

\section{Detention Centre, Vordernberg (Austria)}

The Vordernberg Detention Centre, inaugurated in 2013, is not really a penitentiary structure, but rather a detention centre for illegal immigrants. This specific category of inmates (immigrants without a residence permit) is housed within the centre not due to a sentence passed by a court, but because it finds itself in a condition of illegality that must be resolved either through deportation or the granting of a residence permit. The structure is therefore designed to house, for brief periods of time, people who find themselves in this specific legal status. The structure of the detention centre is based upon the "comb" architectural model and is divided into two main areas: the administrative and management services (administration offices, immigration offices, consulate offices, etc.) are 


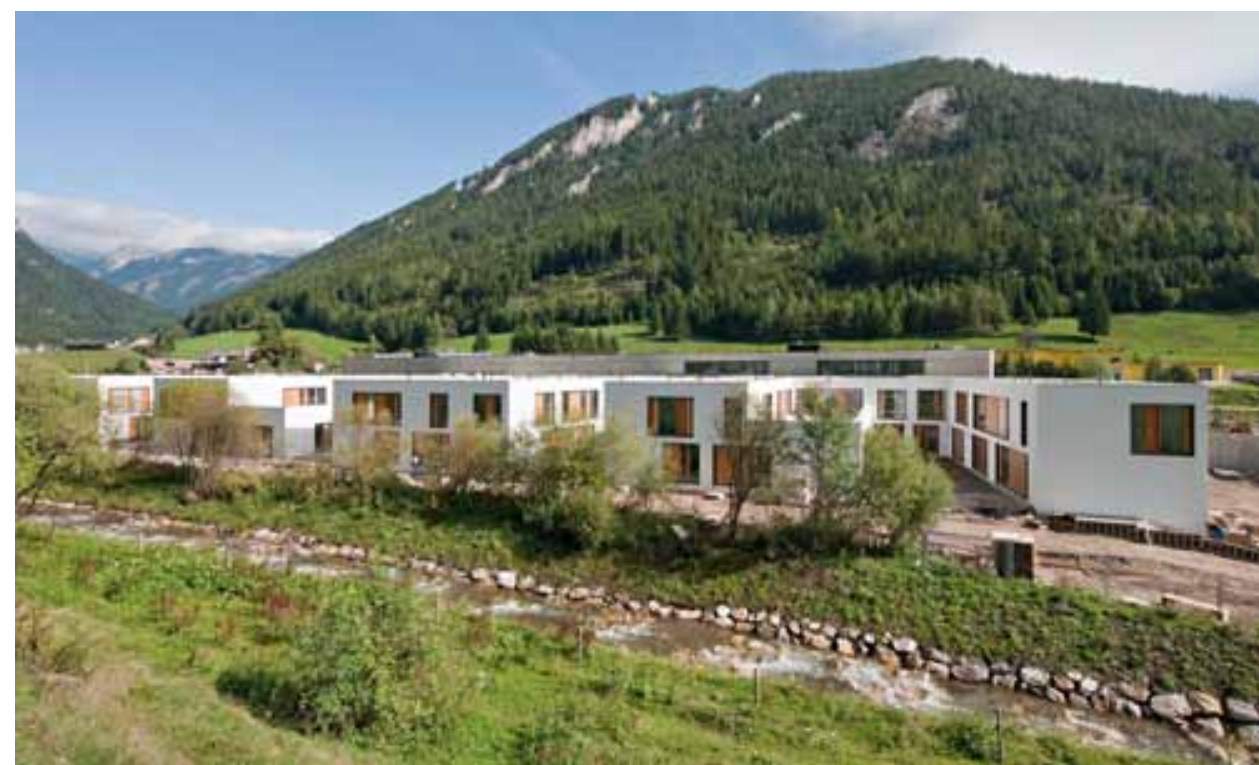

Figure 8.

Detention Center,

Vordernberg.

View of the

residential/detention

zones placed

on the rear

of the building.

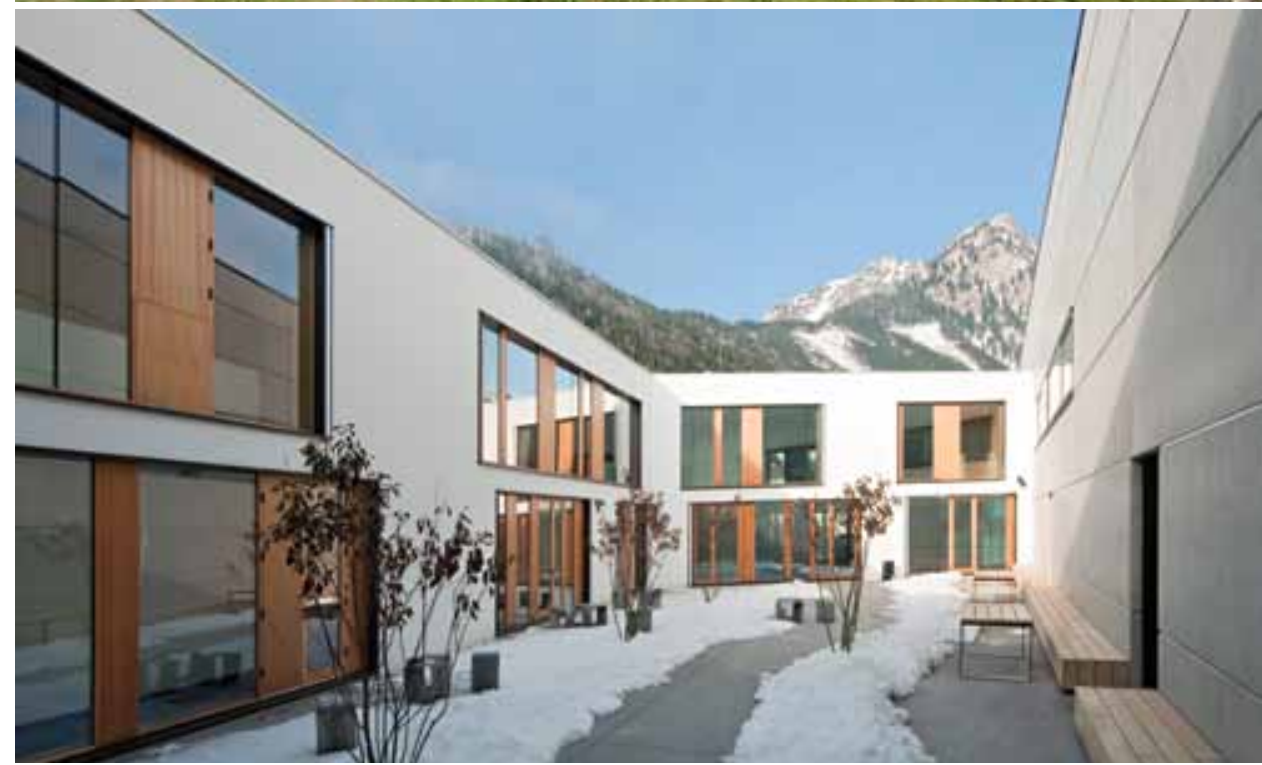

Figure 9.

View of the

residential garden.

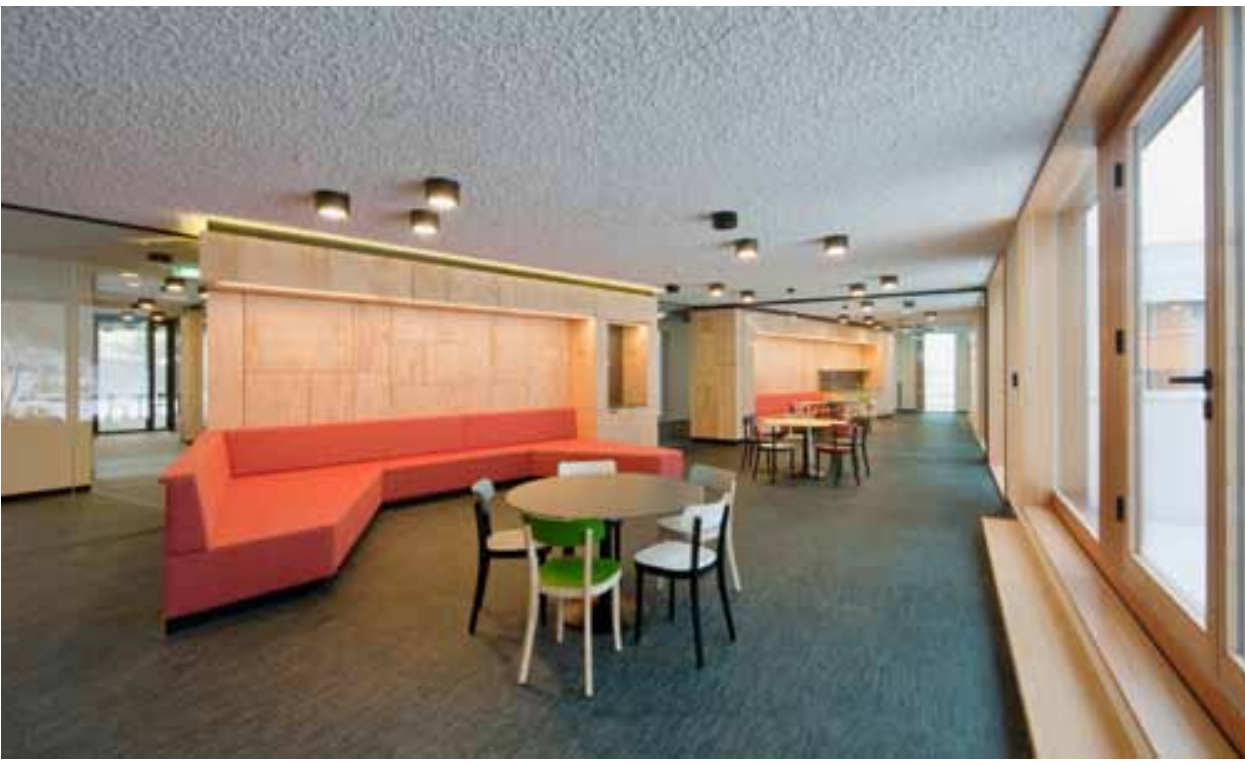

Figure 10.

View of the living/

dining-room

area for the use

of the detainees. 
placed on the side facing the street and the entrance; on the opposite side is the housing area for the residents (Fig. 8), that includes the sleeping quarters and all the spaces for everyday life (living-room, dining-room, kitchen, toilets and bathrooms, etc.). The building, composed of two floors above-ground, includes seven residential sections, each of which has a garden or a terrace (Fig. 9). Open spaces are free to be used by residents upon previous notice to the surveillance personnel (Fig. 10). The building constitutes an interesting example of integration between detention-type security measures (people detained within the structure cannot leave before receiving the necessary documents) and an everyday way of life. The project presentation says that the architects imagined the structure as a simple guesthouse, with ample spaces furnished with high-quality furniture, void of any physical-type security devices (bars on windows, fences, a security wall), capable of both respecting the dignity of the people detained and guaranteeing compliance with security regulations. The aim of the architects was constructing a building that did not evoke the traditional image of a prison (while, however, fulfilling an analogous function) and that respected the rights and needs of the people held within it, allowing them to organise and decide how to spend their time in the structure. The research for the project, developed through a continuous dialogue between the architects and the personnel of the Austrian penitentiary administration, resulted in spatial solutions that can be adopted in future minimum-security prisons as well, that guarantee both a degree of self-determination in the detainees and the respect for detention regime regulations.

\section{CONCLUSIONS}

The critical interpretation of the conceptual elements and of the design approaches regarding the topic of penitentiary architecture proposed above, tries to "mend" the relationship between the theoretical conception and the actual building practice of the prison. The interpretation is developed from the idea that the architectural project, when it materialises in a built structure, is always the material expression of an abstract idea and of a specific vision of the world which manifests itself through the architectural consistency of the building and of the built spaces. This affirmation is even more true when it is referred to the design of institutional architecture, which, in addition to its own function, is called to transfer to society at large a series of meanings and symbolic values, as in the case of courthouses, schools, hospitals and shelters. Among these typologies, the prison is the one which represents in a more evident manner the gap between theoretical thought and concrete results.

Over the past forty years, penitentiary disciplines have undergone radical theoretical changes which, on various occasions, have attempted to modify in society the meaning and the role of the punishment, and 
consequently of the prison. The ideas, theoretical expression of the most recent regulations, had a marginal influence on the quality of the existing penitentiary structures. Therefore, the conception of the building focused on a severe incarceration regime and the refusal to accept the possibility of a more open prison remained mostly unvaried through time. The consequences of the disparity between the "theory of detention" and the "practice of incarceration" has resulted in the fact that Italian penitentiary structures are now so far behind that the European Court of Human Rights based in Strasbourg has condemned Italy for inhuman and debasing treatment of detainees.

In order to restore the rule of law in penitentiaries, institutions have determined different forms of intervention: some programmatic and others of a legislative or scientific and cultural nature. These interventions on the penitentiary building system are both of a quantitative and a qualitative nature. The first are aimed at the construction of additional structures, whereas the latter intervene on the articulation of the building system. The latter is developed according to new building typologies which respond to the new detention models, thus attempting to express the renewed cultural stance that interprets the prison as an element capable of being in synergy with other urban functions. The objectives set by the institutions, expressed through new theoretical developments, represent an ambitious and progressive project aimed at eradicating conservative and backward ideas regarding the role of prison architecture. It proposes a new disciplinary conception of the architectural project open to the academic and professional world in an attempt to solve and make effective the relationship between architectural design, building practices and management of the penitentiary structure. Today, the most difficult task faced by architectural culture is that of being more incisive and successful than before in putting into practice and making effective the theoretical principles that are the expression of the new idea of the prison.

\section{Notes}

1. In this text the terms "detainee" and "inmate" will be used as synonyms, without consideration of the differences which may derive from legal subtleties in certain languages. The same is true for the use of the terms "jail" and "prison," which may also have subtle variations in meaning in different countries.

2. Cf. General Assembly on Criminal Enforcement, 2016.

3. Cf. Soering, 2004.

4. Understood as the place where the sentence is served which was determined by the conviction as a result of a criminal trial carried out in accordance with the law and aimed at safeguarding the rights of all parties involved in an equal and impartial manner.

5. John Howard's most important work, The State of the Prison (1 $1^{\text {st }}$ edition 1777), is an analysis of the conditions and practices carried out within the most important European prisons.

6. The text was published for the first time in 1764 and was widely diffused throughout Europe, thus contributing to set the foundations for the Enlightenment thought and for the new idea of the punishment.

7. Crime was defined by Cesare Beccaria as the violation of the social contract between 
the individual and society, and gradually lost its religious connotation related to sin. 8. In Italy, for example, approximately $45 \%$ of the detainee population is serving a sentence of less than 5 years, whereas only a small percentage is serving sentences of more than 30 years to life (approximately $4 \%$ ) as a result of serious or very serious crimes (Istituto Nazionale di Statistica, 2015).

9. European Committee for the Prevention of Torture, C.P.T., U.N.

10. Prisons today play a triple role: they represent the punishment to be suffered as a consequence of the sentence in proportion of the gravity of the crime committed (retribution), they prevent the commission of crime through fear of the punishment and the certainty of jail (deterrence), and limit the commission of new crimes through re-education and social re-adaptation (recovery and rehabilitation).

11. World Prison Population List, $11^{\text {th }}$ edition, by Roy Walmsley, International Centre for Prison Studies, 2016.

12. By rate of detention is understood the number of detainees for every 100,000 inhabitants.

13. Final Report of Statistical Survey 2015, (Istituto Nazionale di Statistica).

14. The percentage of recidivism refers to the number of detainees who return to prison within two years of being liberated.

15. Sterbenz Christina, "Why Norway's Prison System Is So successful," Business Insider UK, 11 December 2014.

16. Erwin James, "The Norwegian Prison Where Inmates Are Treated like People,"

The Guardian, 25 February 2013.

17. The collective structures used for reference in this text are student housing, nursing homes and convents.

18. See, among others, Parker, E. A., "The social-psychological impact of a college education on the prison inmate," Journal of Correctional Education 41(3) (1990):140-146. 19. General Assembly on Criminal Enforcement, Op. Cit.

20. European Commitee for the Prevention of Torture and Inhuman or Degrading Treatment or Punishment.

21. Antonie C. Quatremère de Quincy, Dizionario storico di architettura: le voci teoriche (Venice, It.: Marsilio, 1985; or. ed.: Paris, 1788-1825, 1832).

22. Giulio C. Argan, Progetto e destino (Milan: II Saggiatore, 1965), 78.

\section{References}

Argan, Giulio C. Progetto e destino. Milan: II Saggiatore, 1965.

Beccaria, Cesare. Dei delitti e delle pene. Rome: Newton, 2012.

Brodie, Allan, Croom, Jane, and James O. Davies. English Prisons. An Architectural History. Swindon (UK): English Heritage, 2002.

Di Gennaro, Giuseppe et al., eds. Prison Architecture. An International Survey of Representative Closed Institution and Analysis of Current Trends in Prison Design. London: The Architectural Press, 1975.

Fairweather, Leslie and Seán McConville. Prison Architecture. Policy, Design and Experience. London: The Architectural Press, 2000.

Foucault, Michel. Surveiller et punir. Naissance de la prison. Paris: Editions Gallimard, 1975. Giostra, Glauco, et al. Stati Generali sull'Esecuzione Penale. Documento finale. Rome: Ministry of Justice, 2016.

Gramsci, Antonio. Lettere dal carcere. Turin (It.): Einaudi, 1971.

Kimme, Dennis A. Jail Design Guide. A Resource for Small and Medium-Sized Jails. Third Edition. Washington DC: U.S. Department of Justice National Institute of Corrections, 2011.

Lenci, Sergio. "Una esperienza di progettazione: il carcere di Rebibbia." Rassegna di studi penitenziari, July/October (1968): 187-217.

Martí Arís, Carlos. "Tipo." In Dizionario critico illustrato delle voci più utili all'architetto moderno. Edited by Luciano Semerani. Ravenna (It.): Faenza Editrice, 1993 (183-194).

Michelucci, Giovanni. "«È certo che sia bene costruire le carceri lontane dalle città?»." 
La Nuova Città 7, no. 2/3, May/December (1998): 7-8.

Nesbit, Kate, ed. Theorizing a New Agenda for Architecture: An Anthology of Architectural Theory 1965-1995. New York: Princeton Architectural Press, 1996.

Pevsner, Nikolaus. A History of Building Types. New York: Princeton University Press, 1976.

Phillips, Todd S. and Michael A. Griebel. Building Type Basics for Justice Facilities. New Jersey: Wiley, 2003.

Quatremère de Quincy, Antonie C. Dizionario storico di architettura: le voci teoriche. Venice, It.: Marsilio, 1985; or. ed.: Paris, 1788-1825, 1832.

Robin, Evans. The Fabrication of Virtue: English Prison Architecture, 1750-1840. Cambridge (UK): Cambridge University Press, 1982.

Soering, Jens. An Expensive Way to Make Bad People Worse: An Essay in Prison Reform from an Insider's Perspective. New York: Lantern Books, 2004.

Spens, Iona, ed. Architecture of Incarceration. Singapore: Academy Editions, 1994.

Wener, Richard E. The Environmental Psychology of Prisons and Jails: Creating Humane Spaces in Secure Settings. Cambridge (UK): Cambridge University Press, 2012.

\section{Credits}

Figures 1, 2, 3: Photos by: ( ) Jiri Hvran, HLM arkitektur as/EMT.

Figures 4, 5, 6, 7: Photos by: (c) Paul Ott, Photografiert.

Figures 8, 9, 10: Photos by: (c) Hertha Hurnaus.

Luigi Vessella is currently a Research Fellow with the Department of Architecture at the University of Florence (Italy). He carries out research within the FP7 program ("7th Framework Programme for Research and Technological Development," a research program of the European Union). In 2015 he earned a PhD in Technology of Architecture with a mention of merit at the PhD Theses Awards granted by the Firenze University Press. From 2011 he collaborates to develop educational activities within the Technology of Architecture course. E-mail: luigi.vessella@gmail.com 